\title{
(6) \\ Social environments, risk-taking and injury in farm adolescents
} OPEN ACCESS

\author{
William Pickett, ${ }^{1}$ Richard L Berg, ${ }^{2}$ Barbara Marlenga ${ }^{3}$
}

\begin{abstract}
${ }^{1}$ Department of Public Health Sciences, Queen's University, Kingston, Ontario, Canada ${ }^{2}$ Biomedical Informatics Research Center, Marshfield Clinic Research Foundation, Marshfield, Wisconsin, USA ${ }^{3}$ National Children's Center for Rural and Agricultural Health and Safety, National Farm Medicine Center, Marshfield Clinic Research Foundation, Marshfield, Wisconsin, USA
\end{abstract}

\section{Correspondence to}

Dr Barbara Marlenga, National Children's Center for Rural and Agricultural Health and Safety, National Farm Medicine Center, Marshfield Clinic Research Foundation, 1000 North Oak Avenue, Marshfield, WI 54449, USA;

marlenga.barbara@mcrf. mfldclin.edu

Received 20 April 2016 Revised 20 December 2016 Accepted 30 December 2016 Published Online First 27 January 2017

\begin{abstract}
Background Farm environments are especially hazardous for young people. While much is known about acute physical causes of traumatic farm injury, little is known about social factors that may underlie their aetiology.

Objectives In a nationally representative sample of
\end{abstract} young Canadians aged 11-15 years, we described and compared farm and non-farm adolescents in terms of the qualities of their social environments, engagement in overt multiple risk-taking as well as how such exposures relate aetiologically to their reported injury experiences.

Methods Cross-sectional analysis of survey reports from the 2014 (Cycle 7) Canadian Health Behaviour in School-Aged Children study was conducted. Children ( $n=2567 ; 2534$ weighted) who reported living or working on farms were matched within schools in a 1:1 ratio with children not living or working on farms. Scales examining quality of social environments and overt risktaking were compared between the two groups, stratified by gender. We then related the occurrence of any serious injury to these social exposures in direct and interactive models.

Results Farm and non-farm children reported social environments that were quite similar, with the exception of overt multiple risk-taking, which was demonstrably higher in farm children of both genders. Engagement in overt risk-taking, but not the other social environmental factors, was strongly and consistently associated with risks for serious injury in farm as well as non-farm children, particularly among males.

Conclusions Study findings highlight the strength of associations between overt multiple risk-taking and injury among farm children. This appears to be a normative aspect of adolescent farm culture.

\section{INTRODUCTION}

Social environments are known determinants of health in young people. Those that are especially relevant to adolescents include aspects of homes and families, communities, schools and peer groups. ${ }^{1}{ }^{2}$ Relationships that develop within such environments are associated with a diversity of physical, mental and social outcomes, as assessed via specific ${ }^{1-5}$ and composite ${ }^{1} 26$ indicators of health status. One possible health outcome is the occurrence of injury.

A major pathway through which social environments relate to adolescent health outcomes, including injury, is engagement in overt risk-taking behaviours. ${ }^{7}$ The CDC has developed frameworks for the assessment of such risk-taking, ${ }^{8}$ and in past research we $\mathrm{e}^{9}{ }^{10}$ and others ${ }^{11}$ have examined the importance of overt risk-taking in the aetiology of injury. Higher risks for injury occur when such behaviours are experienced in clustered manners, commonly referred to as 'multiple risk-taking'.9-11

Associations between adolescent social environments, multiple risk-taking and the occurrence of injuries have special relevance for adolescents who live and work on farms. Farm environments are especially hazardous settings for injuries and associated fatalities. ${ }^{12}{ }^{13}$ In North America, however, there is actually little contemporary evidence on the nature and qualities of adolescent social environments on farms and how they might contribute to injury risks in direct, mediated or interactive ways. Similarly, there is little available information on the extent of risk-taking that occurs in young people from farm versus other adolescent populations, although a number of potential health outcomes of this risk-taking, including injury, are more prevalent among adolescents from farms. ${ }^{12-14}$

In response to these identified gaps in knowledge, we had a unique opportunity to conduct a national study with young Canadians. Our intentions were to describe and compare farm and non-farm adolescents in terms of the qualities of their social environments, engagement in overt risk-taking assessed via a multiple risk behaviour model as well as how such exposures relate to their reported injury experiences. We determined whether adolescents from farms are advantaged or disadvantaged in terms of these potential determinants of health and health outcomes. The analysis was exploratory, although a priori, based on known high rates of traumatic injury, ${ }^{12-14}$ we hypothesised that the farm adolescents might report more hazardous social and behavioural circumstances, and these might be related to elevated risks for injury in direct or interactive manners. Confirmation of such findings would provide direction for health promotion initiatives aimed specifically at farm populations and aimed to promote health and prevent injury in these vulnerable groups.

\section{METHODS}

Cycle 7 of the Canadian Health Behaviour in School-Aged Children (HBSC) study ${ }^{1}{ }^{2}$ was conducted in 2014. It involved participants in all provinces and territories. The national sample was stratified by province/territory, type of school board (public vs separate), urban-rural geographical status, school population size and language of instruction (French or English) with standardised population weights generated to account for oversampling and undersampling in some provinces and territories, and to ensure representativeness nationally by age group and gender. 
Participation was voluntary, and consent (explicit or implicit depending on local protocol) was sought from school administrators, parents and participating students as per national human subject requirements. Ethics clearance was obtained from the Queen's University General Research Ethics Board and from Health Canada and the Public Health Agency of Canada. Participation of adolescents from private schools, home school situations, schools on First Nation or Inuit reserves, street youth not in school and incarcerated youth was not sought, but recent data for 2012-2013 show that enrolment in public schools was approximately $95 \% .{ }^{15}$ Youth not providing informed consent were excluded. Response rates were $100 \%$ at the provincial/territorial level and $77 \%$ at the individual student level.

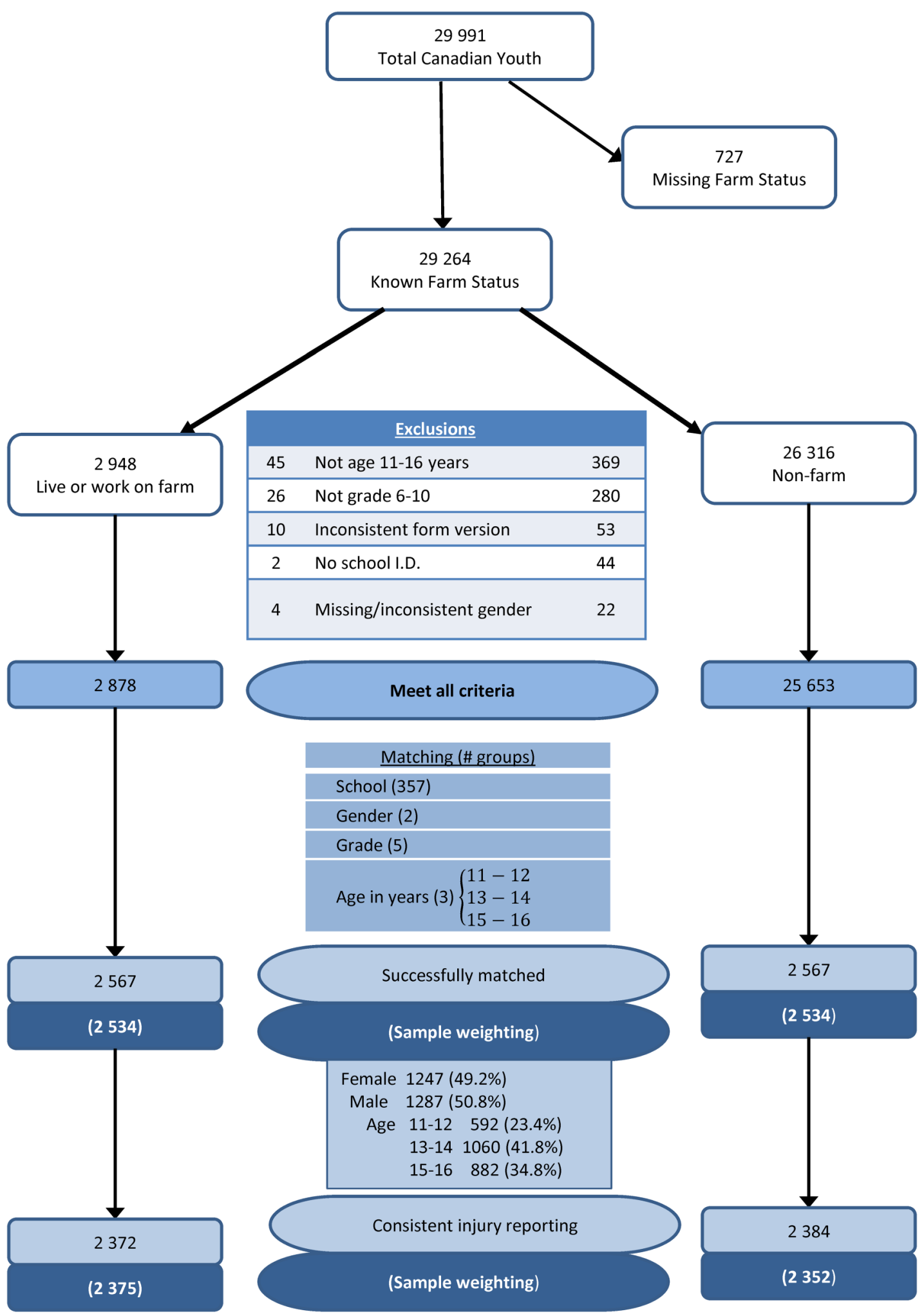

Figure 1 Health Behaviour in School-Aged Children 2013/2014 Canadian Study, Matched Farm Cohort. 


\section{Study design}

The primary goal of this study was to compare injury and its potential social and behavioural determinants between groups of adolescents from farm and non-farm settings. Students who affirmed that they lived or worked on a farm formed our group of primary interest ('farm children'), while other students were eligible for the comparison group ('non-farm children'). Inclusions were as follows: (1) participated in the HBSC survey and provided complete information on all key study variables and (2) aged 11-16 years, in grades 6-10, inclusive. As might be expected, strong geographical differences were observed between farm and non-farm children and there were differences in distribution by gender and age as well. For example, 37\% of farm students in the full sample survey were from Saskatchewan and Manitoba, as compared with $16 \%$ of non-farm students. Only $5 \%$ of farm students were from metropolitan areas, as compared with $14 \%$ of non-farm students. Farm students were more often male (53\% vs $49 \%$ ), and this was particularly true for the oldest students (62\% vs $49 \%$ for those 16 years of age).

To ensure that our comparisons reflect effects of the farm environment with minimal confounding by regional differences and other factors, records for farm children were frequency matched to records in a 1:1 ratio with non-farm children from the same school, by grade (6-10), age (11-12, 13-15, 1516 years) and gender (boy or girl).

\section{Sampling}

The realised Canadian sample (unweighted) consisted of 29991 students from 377 schools, and of these 29264 reported on their farm residential or working status (figure 1). From these, we identified 2948 farm children and 26316 non-farm children. Following exclusions, we identified 2878 farm children and 25653 non-farm children from 357 schools who met the study matching criteria, then we successfully matched 2567 (2534 weighted) of these in a 1:1 farm to non-farm ratio. Complete information including reports of injury experiences was available in 2372 (2375 weighted) farm and 2384 (2352 weighted) non-farm students in the final matched analysis cohort.

\section{Measures}

Demographic information

Participating children reported whether they lived or worked on a farm (yes or no), gender (male vs female) and grade level (610). Months and years of birth and survey administration were used to estimate age in years.

\section{Social environment measures}

Established scales describing social environments each consisted of four or more related items, with Likert-type response options to the questions (eg, 1-'strongly agree' to 5-'strongly disagree').

Family communication scale $(\alpha=0.88)$. This consisted of four items: 'I think the important things are talked about'; 'When I speak someone listens to what I say'; 'We ask questions when we don't understand each other'; 'When there is a misunderstanding we talk it over until it's clear'.

Teacher support scale $(\alpha=0.90)$. This consisted of four items: 'My teachers are interested in me as a student'; 'Most of my teachers are friendly'; 'I am encouraged to express my own views in my class(es)'; 'Our teachers treat us fairly'.

School climate scale $(\alpha=0.79)$. This consisted of four items: 'The rules in this school are fair'; 'Our school is a nice place to be'; 'I feel I belong at this school'; and 'How do you feel about

Table 1 Social and behavioural risk scales by gender and farm status

\begin{tabular}{|c|c|c|c|c|c|c|c|}
\hline & \multicolumn{6}{|c|}{ Female only } & \multirow[b]{5}{*}{ p Value } \\
\hline & \multicolumn{3}{|l|}{ Farm } & \multicolumn{3}{|c|}{ Non-farm } & \\
\hline & \multicolumn{3}{|c|}{$(n=1218)$} & \multicolumn{3}{|c|}{$(n=1218)$} & \\
\hline & \multicolumn{3}{|l|}{$95 \% \mathrm{Cl}$} & \multicolumn{3}{|c|}{$95 \% \mathrm{Cl}$} & \\
\hline & Mean & Lower & Upper & Mean & Lower & Upper & \\
\hline Family communication scale & 2.15 & 2.06 & 2.24 & 2.13 & 2.04 & 2.21 & 0.696 \\
\hline Teacher support scale & 2.27 & 2.19 & 2.34 & 2.23 & 2.17 & 2.30 & 0.518 \\
\hline School climate scale & 2.39 & 2.31 & 2.48 & 2.31 & 2.23 & 2.38 & 0.129 \\
\hline Friend support scale & 1.82 & 1.75 & 1.90 & 1.74 & 1.67 & 1.81 & 0.095 \\
\hline Community support scale & 2.22 & 2.16 & 2.29 & 2.22 & 2.15 & 2.30 & 0.967 \\
\hline \multirow[t]{6}{*}{ Overt risk-taking scale } & 0.44 & 0.40 & 0.48 & 0.38 & 0.33 & 0.42 & 0.041 \\
\hline & \multicolumn{6}{|c|}{ Male only } & \multirow[b]{5}{*}{$p$ Value } \\
\hline & \multicolumn{3}{|l|}{ Farm } & \multicolumn{3}{|c|}{ Non-farm } & \\
\hline & $(n=121$ & & & $(n=12$ & & & \\
\hline & \multicolumn{3}{|l|}{$95 \% \mathrm{Cl}$} & \multicolumn{3}{|c|}{$95 \% \mathrm{Cl}$} & \\
\hline & Mean & Lower & Upper & Mean & Lower & Upper & \\
\hline Family communication scale & 2.06 & 1.99 & 2.13 & 2.04 & 1.97 & 2.11 & 0.688 \\
\hline Teacher support scale & 2.33 & 2.25 & 2.41 & 2.29 & 2.22 & 2.36 & 0.505 \\
\hline School climate scale & 2.52 & 2.43 & 2.61 & 2.39 & 2.30 & 2.49 & 0.062 \\
\hline Friend support scale & 2.16 & 2.07 & 2.26 & 2.13 & 2.05 & 2.21 & 0.528 \\
\hline Community support scale & 2.19 & 2.11 & 2.27 & 2.20 & 2.13 & 2.27 & 0.944 \\
\hline Overt risk-taking scale & 0.55 & 0.50 & 0.60 & 0.43 & 0.39 & 0.47 & $<0.001$ \\
\hline
\end{tabular}


school at present?' (1-'I don't like it at all' to 4-'I like it a lot').

Friend support scale $(\alpha=0.93)$. This consisted of four items: 'My friends really try to help me'; 'I can count on my friends when things go wrong'; 'I have friends with whom I can share my joys and sorrows'; 'I can talk about my problems with my friends'.

Community support scale $(\alpha=0.79)$. This consisted of five items: "People say "hello" and often stop to talk to each other on the street'; 'It is safe for younger children to play outside during the day'; 'You can trust people around here'; 'There are good places to spend your free time (eg, recreation centres, parks, shopping centres)'; 'I could ask for help or a favour from neighbours'.

\section{Individual measures}

Multiple risk-taking scale $(\alpha=0.78)$. We combined six individual items into a composite scale of overt multiple risk-taking by applying the follow coding structure: (1-'no engagement in the risk behaviour'; 2-'moderate levels of engagement'; 3 - 'high levels of engagement') and using standard cutpoints (Kwong J, Klinger DA, Janssen I, Pickett W. Adolescent risk taking in Canada: new insights about an old framework, 2016 manuscript submitted). Risk behaviours included in this scale were as follows: 'lifetime smoking history'; 'use of alternative smoking products'; 'frequency of alcohol consumption'; 'lifetime drunkenness history'; 'bicycle helmet use'; 'energy drink consumption'.

Table 2 Overt risk-taking by gender for farm and non-farm children

\begin{tabular}{|c|c|c|c|c|c|}
\hline \multirow[b]{3}{*}{ Overt risk-taking scale } & \multicolumn{5}{|c|}{ Female only } \\
\hline & & \multicolumn{2}{|c|}{ Farm } & \multicolumn{2}{|c|}{ Non-farm } \\
\hline & & $\mathbf{n}$ & $\%$ & $\mathbf{n}$ & $\%$ \\
\hline \multirow[t]{4}{*}{ None/minimal } & 0 & 198 & 17.4 & 279 & 24.7 \\
\hline & 0.25 & 489 & 43.0 & 461 & 40.9 \\
\hline & 0.5 & 141 & 12.4 & 126 & 11.2 \\
\hline & 0.75 & 137 & 12.1 & 132 & 11.7 \\
\hline \multirow[t]{4}{*}{ Moderate } & 1 & 45 & 3.9 & 43 & 3.8 \\
\hline & 1.25 & 76 & 6.7 & 41 & 3.7 \\
\hline & 1.5 & 7 & 0.6 & 21 & 1.8 \\
\hline & 1.75 & 43 & 3.8 & 24 & 2.1 \\
\hline \multirow[t]{5}{*}{ Frequent } & 2 & 1 & 0.1 & 0 & 0.0 \\
\hline & \multicolumn{5}{|c|}{ Farm vs non-farm $p=0.041$} \\
\hline & \multicolumn{5}{|c|}{ Male only } \\
\hline & & \multicolumn{2}{|c|}{ Farm } & \multicolumn{2}{|c|}{ Non-farm } \\
\hline & & $\mathrm{n}$ & $\%$ & $\mathbf{n}$ & $\%$ \\
\hline \multirow[t]{4}{*}{ None/minimal } & 0 & 141 & 12.8 & 258 & 23.6 \\
\hline & 0.25 & 441 & 40.1 & 388 & 35.5 \\
\hline & 0.5 & 113 & 10.3 & 140 & 12.8 \\
\hline & 0.75 & 166 & 15.1 & 163 & 14.9 \\
\hline \multirow[t]{4}{*}{ Moderate } & 1 & 36 & 3.3 & 32 & 3.0 \\
\hline & 1.25 & 110 & 10.0 & 63 & 5.7 \\
\hline & 1.5 & 18 & 1.6 & 18 & 1.6 \\
\hline & 1.75 & 63 & 5.7 & 21 & 1.9 \\
\hline \multirow[t]{2}{*}{ Frequent } & 2 & 12 & 1.1 & 10 & 0.9 \\
\hline & \multicolumn{5}{|c|}{ Farm vs non-farm $p=0.001$} \\
\hline
\end{tabular}

Medically treated injuries. Using a module adapted from US population health surveys, ${ }^{16}$ students were asked to report the occurrence of medically treated injuries in the previous year. First, they were asked an initial screening question: 'During the past 12 months, how many times were you injured and had to be treated by a doctor or nurse?' ('I was not injured', 'one time', 'two times', 'three times', 'four times or more'). Students reporting one or more injuries were asked supplemental questions about their most serious injury event. Severe injuries were those that required hospital admission overnight, an operation, casts or stitching.

\section{Statistical analysis}

Data analyses were conducted with SAS V.9.3 (SAS Institute, Cary, North Carolina, USA 2012). Descriptive analyses were used to characterise the final samples of farm and non-farm children by age, gender and grade. In our primary analyses, we used procedures for linear and logistic regression analysis of complex survey data (PROC SURVEYREG and PROC SURVEYLOGISTIC) to compare the farm and matched non-farm groups with respect to each of the five scales describing social environments and the overt risk-taking scale. Each scale is ordered, with a large number of possible outcomes based on the number of questions incorporated. Only those with all questions complete for a scale were included in the analyses of that scale. Although the full scales were used in all regression analyses, for presentation in tables the scales have

Table 3 Annual prevalence of injury by gender and age group for farm and non-farm children

\begin{tabular}{|c|c|c|c|c|}
\hline & \multicolumn{4}{|c|}{ Female only } \\
\hline & \multicolumn{2}{|l|}{ Farm } & \multicolumn{2}{|c|}{ Non-farm } \\
\hline & $\mathrm{n}$ & $\%$ & $\mathrm{n}$ & $\%$ \\
\hline \multicolumn{5}{|l|}{ Ages $11-12$} \\
\hline Any injury & 112 & 40.4 & 96 & 36.2 \\
\hline Severe injury & 38 & 13.7 & 46 & 17.3 \\
\hline \multicolumn{5}{|l|}{ Ages 13-14 } \\
\hline Any injury & 260 & 51.7 & 204 & 40.6 \\
\hline Severe injury & 112 & 22.2 & 65 & 13.0 \\
\hline \multicolumn{5}{|l|}{ Ages 15-16 } \\
\hline Any injury & 193 & 46.0 & 143 & 35.6 \\
\hline Severe injury & 64 & 15.2 & 56 & 14.1 \\
\hline \multicolumn{5}{|c|}{ Farm vs non-farm comparisons: any injury $p=0.004$} \\
\hline & \multicolumn{4}{|c|}{ Severe $p=0.004$} \\
\hline & \multicolumn{4}{|c|}{ Male only } \\
\hline & \multicolumn{2}{|l|}{ Farm } & \multicolumn{2}{|c|}{ Non-farm } \\
\hline & $\mathrm{n}$ & $\%$ & n & $\%$ \\
\hline \multicolumn{5}{|l|}{ Ages 11-12 } \\
\hline Any injury & 145 & 52.9 & 128 & 46.1 \\
\hline Severe injury & 75 & 27.2 & 46 & 16.5 \\
\hline \multicolumn{5}{|l|}{ Ages 13-14 } \\
\hline Any injury & 277 & 57.0 & 207 & 41.8 \\
\hline Severe injury & 147 & 30.3 & 71 & 14.3 \\
\hline \multicolumn{5}{|l|}{ Ages 15-16 } \\
\hline Any injury & 196 & 47.5 & 177 & 42.7 \\
\hline Severe injury & 112 & 27.0 & 89 & 21.5 \\
\hline \multicolumn{5}{|c|}{ Farm vs non-farm comparisons: any injury $\mathrm{p}=0.002$} \\
\hline & \multicolumn{2}{|c|}{ Severe $p<0.001$} & & \\
\hline
\end{tabular}


been grouped to reduce the number of categories. All analyses were adjusted for the weighting and clustering of the complex HBSC sampling design. Analyses were stratified by gender, and age was additionally controlled (beyond the matching described above) with covariates in the regression models using a restricted cubic spline to allow for flexible age trends.

\section{RESULTS}

Figure 1 shows the samples selected for study. The two groups, farm and non-farm children $(n=2534$ matched children in each group), were almost perfectly balanced on the three matching criteria of age, gender and school grade.

Adjusted mean levels of the six different scales describing adolescent social environments and overt multiple risk-taking are described in table 1 . Mean levels of the five social environment scales did not vary consistently between farm and non-farm children, with the exception of a slightly higher 'school climate' perceived by male farm children $(p=0.062)$. However, adjusted mean levels of reported engagement in overt risk-taking were higher among farm versus non-farm children in both females $(p=0.041)$ and males $(p<0.001)$. These associations are more fully illustrated by considering the overt risktaking scale categorically (table 2 ). For example, $12.8 \%$ of male farm children reported no overt risk-taking as compared with $23.6 \%$ of male non-farm children.

Table 3 describes reported injuries within the two study groups. The prevalence of injury was consistently higher among farm children than non-farm children, and this relationship was stronger among male respondents.
Findings from our models that examined relationships between overt risk-taking, farm versus non-farm status and injury are summarised in table 4 . Overt risk-taking was found to be associated with injury, particularly in male children, and most strongly in the farm group. School climate, the social scale showing the most evidence of farm versus non-farm differences, is presented for comparison in table 5. While this scale shows some association with injury among males, the associations between social environments and injury were much weaker than those observed for risk-taking and injury.

\section{DISCUSSION}

Adolescents who live and work on farms are at higher risk for traumatic injury relative to others. ${ }^{12}{ }^{13}$ While past research has shown that much of this is attributable to acute physical hazards, including the dangers of tractors and other farm vehicles, ${ }^{17}$ mechanisation ${ }^{12}{ }^{13}$ fall hazards, ${ }^{18}$ chemical exposures ${ }^{19}$ and blunt animal trauma, ${ }^{20}$ less is known about the social factors that underlie the deeper aetiology of farm injuries. Our study fills an important void in this literature by providing new evidence surrounding social determinants of childhood farm injury, as identified in a national and population-based sample of young people in Canada.

The consistency of the qualities of social environments reported by farm and non-farm adolescents was rather remarkable, as evident in equivalence in the scales describing families, schools, peer groups and communities. Indeed, farm and non-farm children, irrespective of gender, generally reported similar experiences in terms of their perceived social environments. This suggests that farm children are not particularly

Table 4 Overt risk-taking scale by injury severity

\begin{tabular}{|c|c|c|c|c|c|c|c|}
\hline \multirow[b]{3}{*}{ Overt risk-taking scale } & \multicolumn{7}{|l|}{ Female only } \\
\hline & & \multicolumn{3}{|l|}{ Farm } & \multicolumn{3}{|l|}{ Non-farm } \\
\hline & & $\begin{array}{l}\text { No treated injury } \\
(n=580) \\
\%\end{array}$ & $\begin{array}{l}\text { No serious injury } \\
(n=325) \\
\%\end{array}$ & $\begin{array}{l}\text { Serious injury } \\
(n=199) \\
\%\end{array}$ & $\begin{array}{l}\text { No treated injury } \\
(n=643) \\
\%\end{array}$ & $\begin{array}{l}\text { No serious injury } \\
(n=262) \\
\%\end{array}$ & $\begin{array}{l}\text { Serious injury } \\
(n=161) \\
\%\end{array}$ \\
\hline \multirow[t]{2}{*}{ None/minimal } & 0 & 43.2 & 31.9 & 37.9 & 45.0 & 49.5 & 44.0 \\
\hline & 0.5 & 39.3 & 45.2 & 36.9 & 40.3 & 36.8 & 31.7 \\
\hline \multirow[t]{2}{*}{ Moderate } & 1 & 12.3 & 15.1 & 11.1 & 9.7 & 10.7 & 13.9 \\
\hline & 1.5 & 5.1 & 6.4 & 10.6 & 3.4 & 2.3 & 10.2 \\
\hline \multirow[t]{7}{*}{ Frequent } & 2 & 0.1 & 1.4 & 3.6 & 1.6 & 0.6 & 0.2 \\
\hline & Scale mean & 0.39 & 0.50 & 0.51 & 0.038 & 0.34 & 0.47 \\
\hline & $(95 \% \mathrm{Cl})$ & $(0.34-0.44)$ & $(0.42-0.58)$ & $(0.41-0.61)$ & $(0.32-0.44)$ & $(0.29-0.40)$ & $(0.34-0.60)$ \\
\hline & \multicolumn{4}{|c|}{ Association with injury: farm $p=0.018$} & \multicolumn{3}{|l|}{ Non-farm $p=0.183$} \\
\hline & \multicolumn{7}{|l|}{ Male only } \\
\hline & & \multicolumn{3}{|l|}{ Farm } & \multicolumn{3}{|l|}{ Non-farm } \\
\hline & & $\begin{array}{l}\text { No treated injury } \\
(n=478)\end{array}$ & $\begin{array}{l}\text { No serious injury } \\
(\mathrm{n}=261)\end{array}$ & $\begin{array}{l}\text { Serious injury } \\
(\mathrm{n}=290)\end{array}$ & $\begin{array}{l}\text { No treated injury } \\
(\mathrm{n}=586)\end{array}$ & $\begin{array}{l}\text { No serious injury } \\
(\mathrm{n}=276)\end{array}$ & $\begin{array}{l}\text { Serious injury } \\
(\mathrm{n}=169)\end{array}$ \\
\hline Overt risk-taking scale & & $\%$ & $\%$ & $\%$ & $\%$ & $\%$ & $\%$ \\
\hline \multirow[t]{2}{*}{ None/minimal } & 0 & 38.5 & 29.0 & 20.6 & 45.1 & 40.3 & 28.2 \\
\hline & 0.5 & 42.9 & 42.6 & 38.1 & 38.0 & 39.4 & 41.4 \\
\hline \multirow[t]{2}{*}{ Moderate } & 1 & 11.8 & 17.7 & 15.8 & 9.7 & 12.8 & 21.2 \\
\hline & 1.5 & 4.2 & 8.5 & 19.3 & 5.3 & 4.7 & 8.2 \\
\hline \multirow[t]{4}{*}{ Frequent } & 2 & 2.5 & 2.2 & 6.2 & 1.9 & 2.8 & 1.0 \\
\hline & Scale mean & 0.43 & 0.56 & 0.74 & 0.39 & 0.47 & 0.51 \\
\hline & $(95 \% \mathrm{Cl})$ & $(0.37-0.49)$ & $(0.47-0.64)$ & $(0.65-0.83)$ & $(0.33-0.44)$ & $(0.38-0.55)$ & $(0.41-0.62)$ \\
\hline & \multicolumn{4}{|c|}{ Association with injury: farm $p<0.001$} & \multicolumn{3}{|l|}{ Non-farm $p=0.039$} \\
\hline
\end{tabular}


Table 5 School climate scale by injury severity

\begin{tabular}{|c|c|c|c|c|c|c|c|}
\hline \multirow[b]{3}{*}{ School climate scale } & \multicolumn{7}{|l|}{ Female only } \\
\hline & & \multicolumn{3}{|l|}{ Farm } & \multicolumn{3}{|l|}{ Non-farm } \\
\hline & & $\begin{array}{l}\text { No treated injury } \\
(\mathrm{n}=627) \\
\%\end{array}$ & $\begin{array}{l}\text { No serious injury } \\
(n=346) \\
\%\end{array}$ & $\begin{array}{l}\text { Serious injury } \\
(n=205) \\
\%\end{array}$ & $\begin{array}{l}\text { No treated injury } \\
(n=698) \\
\%\end{array}$ & $\begin{array}{l}\text { No serious injury } \\
(n=271) \\
\%\end{array}$ & $\begin{array}{l}\text { Serious injury } \\
(n=159) \\
\%\end{array}$ \\
\hline \multirow[t]{2}{*}{ Strongly agree } & 1 & 7.7 & 6.7 & 4.0 & 8.8 & 11.0 & 9.9 \\
\hline & 1.5 & 17.6 & 15.8 & 14.8 & 18.8 & 12.8 & 13.1 \\
\hline \multirow[t]{2}{*}{ Agree } & 2 & 25.3 & 25.2 & 26.8 & 25.7 & 27.4 & 18.0 \\
\hline & 2.5 & 21.5 & 16.0 & 19.6 & 23.5 & 22.6 & 19.8 \\
\hline \multirow[t]{2}{*}{ Neutral } & 3 & 13.5 & 17.3 & 12.2 & 8.8 & 11.2 & 20.8 \\
\hline & 3.5 & 8.1 & 9.1 & 11.2 & 10.2 & 7.2 & 10.2 \\
\hline \multirow[t]{2}{*}{ Disagree } & 4 & 4.7 & 5.7 & 4.7 & 3.6 & 3.8 & 5.8 \\
\hline & 4.5 & 1.4 & 4.0 & 5.1 & 0.5 & 3.1 & 1.1 \\
\hline \multirow[t]{7}{*}{ Strongly disagree } & 5 & 0.2 & 0.2 & 1.6 & 0.2 & 0.9 & 1.2 \\
\hline & Scale mean & 2.33 & 2.43 & 2.5 & 2.25 & 2.32 & 2.48 \\
\hline & $(95 \% \mathrm{Cl})$ & $(2.21-2.44)$ & $(2.27-2.59)$ & $(2.33-2.67)$ & $(2.16-2.34)$ & $(2.17-2.47)$ & $(2.25-2.71)$ \\
\hline & \multicolumn{4}{|c|}{ Association with injury: farm $p=0.229$} & \multicolumn{3}{|l|}{ Non-farm $p=0.151$} \\
\hline & & \multicolumn{6}{|l|}{ Male only } \\
\hline & & \multicolumn{3}{|l|}{ Farm } & \multicolumn{3}{|l|}{ Non-farm } \\
\hline & & $\begin{array}{l}\text { No treated injury } \\
(n=523)\end{array}$ & $\begin{array}{l}\text { No serious injury } \\
(n=277)\end{array}$ & $\begin{array}{l}\text { Serious injury } \\
(\mathrm{n}=322)\end{array}$ & $\begin{array}{l}\text { No treated injury } \\
(n=650)\end{array}$ & $\begin{array}{l}\text { No serious injury } \\
(n=300)\end{array}$ & $\begin{array}{l}\text { Serious injury } \\
(n=195)\end{array}$ \\
\hline School climate scale & & $\%$ & $\%$ & $\%$ & $\%$ & $\%$ & $\%$ \\
\hline \multirow[t]{2}{*}{ Strongly agree } & 1 & 11.4 & 8.8 & 3.7 & 11.1 & 7.8 & 4.8 \\
\hline & 1.5 & 13.5 & 18.0 & 8.4 & 14.6 & 14.5 & 11.1 \\
\hline \multirow[t]{2}{*}{ Agree } & 2 & 24.8 & 25.9 & 23.7 & 25.6 & 29.0 & 25.6 \\
\hline & 2.5 & 19.6 & 15.9 & 17.5 & 20.2 & 17.7 & 18.9 \\
\hline \multirow[t]{2}{*}{ Neutral } & 3 & 8.9 & 9.4 & 21.2 & 14.8 & 15.5 & 13.1 \\
\hline & 3.5 & 10.4 & 11.3 & 9.5 & 7.1 & 7.7 & 11.7 \\
\hline \multirow[t]{2}{*}{ Disagree } & 4 & 5.6 & 8.4 & 9.2 & 3.9 & 3.9 & 11.9 \\
\hline & 4.5 & 2.5 & 1.8 & 3.8 & 1.1 & 2.4 & 1.7 \\
\hline \multirow[t]{4}{*}{ Strongly disagree } & 5 & 3.4 & 0.5 & 3.0 & 1.5 & 1.5 & 1.2 \\
\hline & Scale mean & 2.42 & 2.40 & 2.72 & 2.30 & 2.38 & 2.59 \\
\hline & $(95 \% \mathrm{Cl})$ & $(2.27-2.57)$ & $(2.24-2.55)$ & $(2.54-2.90)$ & $(2.19-2.41)$ & $(2.22-2.55)$ & $(2.39-2.80)$ \\
\hline & \multicolumn{4}{|c|}{ Association with injury: farm $p<0.013$} & \multicolumn{3}{|l|}{ Non-farm $p=0.033$} \\
\hline
\end{tabular}

unique in terms of the social influences under which they grow and develop as compared with children from the same school. Given this finding, elevations in risks for injury and associated health outcomes observed among farm versus non-farm children are unlikely to be solely attributable to the direct influences of these social environments.

In addition, in both farm and non-farm settings, we identified weak or non-significant associations between the occurrence of medically treated injuries (both serious and non-serious) and the quality of the social environments, as measured by the family, community, school and peer-group scales. This may be attributable to a lack of direct effects, or alternatively, incomplete measurement of the constructs that contributed to these scales and associated concepts. Furthermore, it does not appear that risktaking was an intermediate step in a pathway that linked social environments to the occurrence of injury in our situation, as the basic elements of such a mediation model were not fulfilled in this analysis.

We did observe very strong increases in risk-taking behaviours reported by farm versus non-farm children. This was observed for both individual and composite risk-taking measures using scaled items adapted from an existing CDC framework. ${ }^{8}$ Engagement in these risk behaviours, especially in a clustered manner, has known social origins. $^{21}$ Comparisons included some behaviours with psychoactive properties (two indicators of alcohol misuse) and others that are more generic markers of a high-risk lifestyle (tobacco use, helmet use, energy drink consumption). It is, therefore, biologically ${ }^{22}$ and socially ${ }^{23}$ plausible that such behaviours could contribute to injury risks through both direct (eg, impairment and psychoactive effects) and indirect (risk-taking lifestyles) pathways.

More speculatively, it is also plausible that such reports may be markers of a culture on farms that by choice due to social norms, or by necessity due to the inherent level of risk typical of farm environments, has a tendency to be more accepting of adolescent risk-taking. When combined with the physical hazards inherent to farm work environments, ${ }^{24}$ such risk-taking tendencies may interact to produce higher risks for injury, both intentional and unintentional. This too was borne out in our findings, where we observed strong increases in risk for serious injury associated with living or working on a farm, and interactive effects where farm children who engaged in frequent risktaking also reported the highest levels of injury risk. This culture of risk-taking, as evidenced by engagement in multiple, clustered risk behaviours, does appear to be normative and potentially very important aetiologically. 
Strengths of our analysis warrant comment. Our analysis was large and national in scope; it applied measures that have been tested and used in multiple adolescent health survey cycles in Canada and internationally; ${ }^{12}$ and the study design was robust and accounted for several known confounders of aetiological importance. We also argue that the main study finding, that overt risk-taking as opposed to social environments per se may play a dominant role in the aetiology of paediatric farm injury, is novel and has not been emphasised in the modern prevention literature.

Limitations include our reliance on self-reports, which can be problematic for items with a social stigma attached to them (eg, family factors, some risk behaviours). Misclassification of such items is likely to be non-differential by outcome status, possibly leading to attenuation of effects. Similarly, by necessity our measures of social environment (eg, school climate) relied on the assessments of individual students, and all survey responses to some degree rely on the recall of the individual students. In addition, due to the natures of the risk behaviour and injury items available to us, we were unaware of whether or not injury events were caused directly by psychoactive impairment of the young people involved, nor did we have the ability to study specific types of injury in isolation. This too may have biased effects towards the null. Finally, the cross-sectional nature of our research design limited our ability to observe the temporal direction of identified associations, and the associations that were identified should not necessarily be viewed as causal.

\section{CONCLUSION}

Most Canadian farms contain many hazards that leave children who live and work on them at risk for traumatic injury. Beyond such hazards, little is known about determinants of injury in farm children. Contrary to our initial expectations, our analysis suggested that there is little about the social environments on farms relative to other settings that predispose young people to injury. The one exception to this was overt risk-taking, and our findings were clear, crossed both genders and engagement in these behaviours was strongly related to the occurrence of medically treated injury. This suggests a clear need for focus on the culture surrounding risk-taking in farm adolescent environments as a primary approach to prevention. Innovative solutions are required to address this troubling cultural phenomenon.

\section{What is already known on the subject}

- Farm environments are especially hazardous settings for adolescent injury and associated fatalities.

- Individual and contextual aspects of social environments are potential determinants of adolescent injury.

\section{What this study adds}

- Farm adolescents report very similar social environments to their non-farm peers.

- Farm adolescents report more frequent engagement in overt multiple risk-taking than their non-farm peers.

- Overt risk-taking, but not other social environmental factors, was strongly related to the occurrence of serious injury in farm adolescents.
Acknowledgements The authors thank Matthew King (Canadian HBSC national coordinator) and John Freeman (Canadian HBSC coprincipal investigator), both of Queen's University, Canada, and Jo Inchley (University of St Andrews, Scotland, international HBSC coordinator) and Oddrun Samdal (University of Bergen, Norway, international HBSC data coordinator).

Contributors WP contributed to this manuscript as follows: (1) substantial contributions to conception and design, data acquisition, codirection of the statistical analysis, codirection of interpretation of data; (2) drafted major portions of the article; (3) provided final approval of the version to be published. RLB contributed to this manuscript as follows: (1) substantial contributions to conception and design, creation of the dataset for analysis, conduct and presentation of the statistical analysis, codirection of interpretation of data; (2) revised the article critically for important intellectual content; (3) provided final approval of the version to be published. BM contributed to this manuscript as follows: (1) substantial contributions to conception and design, codirection of the statistical analysis, codirection of interpretation of data; (2) revised the article critically for important intellectual content; (3) provided final approval of the version to be published.

Funding The Public Health Agency of Canada and Health Canada funded Cycle 7 of the Health Behaviour in School-Aged Children study in Canada. Additional support for this analysis included operating grants from the Canadian Institutes of Health Research and the Heart and Stroke Foundation of Canada (MOP 97962; PCR 101415), as well as the CDC/National Institute for Occupational Health and Safety (2U54OH009568).

\section{Competing interests None declared.}

Ethics approval Queen's University General Research Ethics Board and from Health Canada and the Public Health Agency of Canada.

Provenance and peer review Not commissioned; externally peer reviewed.

Open Access This is an Open Access article distributed in accordance with the Creative Commons Attribution Non Commercial (CC BY-NC 4.0) license, which permits others to distribute, remix, adapt, build upon this work non-commercially, and license their derivative works on different terms, provided the original work is properly cited and the use is non-commercial. See: http://creativecommons.org/ licenses/by-nc/4.0/

\section{REFERENCES}

1 Freeman JG, Luu K. Mental health. In: Freeman JG, King M, Pickett W, et al, eds. The health of Canada's young people: a mental health focus. Ottawa: Public Health Agency of Canada, 2011:11-28. Cat no: hP15-13/2011E-PDF. ISBN: hP15-13/ 2011E.

2 Currie C, Nic Gabhainn S, Godeau E, et al. The Health Behaviour in School-Aged Children: WHO Collaborative Cross-National (HBSC) study: origins, concept, history and development 1982-2008. Int J Public Health 2009;54(Suppl 2):131-9.

3 Viner RM, Ozer EM, Denny S, et al. Adolescence and the social determinants of health. Lancet 2012:379:1641-52.

4 Elgar FJ, Craig W, Trites SJ. Family dinners, communication, and mental health in Canadian adolescents. J Adolesc Health 2013;52:433-8.

5 O'Connell P, Pepler D, Craig W. Peer involvement in bullying: insights and challenges for intervention. J Adolesc 1999:22:437-52.

6 Davison C, Michaelson V, Pickett W. It still takes a village: an epidemiological study of the role of social supports in understanding unexpected health states in young people. BMC Public Health 2015;15:295

7 Jessor R. Risk behavior in adolescence: a psychosocial framework for understanding and action. J Adolesc Health 1991:12:597-605.

8 Brener ND, Kann L, Shanklin S, et al. Methodology of the youth risk behavior surveillance system-2013. MMWR Recomm Rep 2013:62:1-20.

9 Pickett W, Schmid H, Boyce WF, et al. Multiple risk behavior and injury: an international analysis of young people. Arch Pediatr Adolesc Med 2002;156:786-93.

10 Pickett W, Garner MJ, Boyce WF, et al. Gradients in risk for youth injury associated with multiple-risk behaviours: a study of 11,329 Canadian adolescents. Soc Sci Med 2002:55:1055-68.

11 Russell K, Davison C, King N, et al. Understanding clusters of risk factors across different environmental and social contexts for the prediction of injuries among Canadian youth. Injury 2016;47:1143-50.

12 Pickett W, Hartling L, Dimich-Ward $\mathrm{H}$, et al. Surveillance of hospitalized farm injuries in Canada. Inj Prev 2001;7:123-8.

13 Pickett W, Hartling L, Brison RJ, et al. Fatal work-related farm injuries in Canada, 1991-1995. Canadian Agricultural Injury Surveillance Program. CMAJ 1999; 160:1843-8.

14 Brison RJ, Pickett W, Berg RL, et al. Fatal agricultural injuries in preschool children: risks, injury patterns and strategies for prevention. CMAJ 2006;174:1723-6.

15 Van Pelt D, Clemens J, Brown B, et al. Where our students are educated: measuring student enrolment in Canada. Fraser Institute, 2015. https://www.fraserinstitute.org/ studies/where-our-students-are-educated-measuring-student-enrolment-in-canada 
16 Scheidt PC, Harel Y, Trumble AC, et al. The epidemiology of nonfatal injuries among US children and youth. Am J Public Health 1995;85:932-8.

17 Marlenga B, Pickett W, Berg RL, et al. Operational characteristics of tractors driven by children on farms in the United States and Canada. J Agric Saf Health 2004;10:17-25.

18 Pickett W, Dostaler S, Berg RL, et al. Pediatric fall injuries in agricultural settings: a new look at a common injury control problem. J Occup Environ Med 2007:49:461-8.

19 Klein-Schwartz W, Smith GS. Agricultural and horticultural chemical poisonings: mortality and morbidity in the United States. Ann Emerg Med 1997;29:232-8.
20 Busch HM Jr, Cogbill TH, Landercasper J, et al. Blunt bovine and equine trauma. J Trauma 1986;26:559-60.

21 Jackson $C A$, Henderson M, Frank JW, et al. An overview of prevention of multiple risk behaviour in adolescence and young adulthood. J Public Health 2012;34:i31-40.

22 Sindelar HA, Barnett NP, Spirito A. Adolescent alcohol use and injury. A summary and critical review of the literature. Minerva Pediatr 2004:56:291-309.

23 Petridou E, Zavitsanos X, Dessypris N, et al. Adolescents in high-risk trajectory: clustering of risky behavior and the origins of socioeconomic health differentials. Prev Med 1997;26:215-19.

24 Pickett W, Hagel L, Dosman JA, et al. Safety features on agricultural machines and farm structures in Saskatchewan. J Agromedicine 2012;17:421-4.

\section{Reducing injury deaths increases life expectancy}

Researchers at the $C D C$ estimate that without injury deaths, the average life expectancy at birth in the USA could be increased by 1.5 years. They found that these deaths in New York State were $28.6 \%$ below the national rate. If the national injury death rate could be reduced to that of this State, about 48400 injury deaths would be prevented annually.

\section{US study prompts calls for Australian sports injury register}

A study in JAMA found signs of the degenerative brain disease chronic traumatic encephalopathy in $99 \%$ of former National Football League players whose brains were donated for research. This prompted the Australian Centre for Research into Injury in Sport and its Prevention to suggest that better surveillance of sporting injuries would help inform and evaluate current safety measures. 